Revista Cientifica Arbitrada de la Fundación MenteClara

Artículos atravesados por (o cuestionando) la idea del sujeto -y su género- como una construcción psicobiológica de la cultura Articles driven by (or questioning) the idea of the subject -and their gender- as a cultural psychobiological construction

Vol. 1 (2), 2016

ISSN 2469-0783

https://datahub.io/dataset/2016-1-2-e07

\title{
DEMOCRACIA, REPÚBLICA Y LIBERTAD. APROXIMACIONES DESDE LA TEORÍA POLÍTICA MODERNA E IRRADIACIONES DEL PENSAMIENTO POLÍTICO ARGENTINO
}

\author{
DEMOCRACY, REPUBLIC, AND FREEDOM. APPROACHES FROM MODERN \\ POLITICAL THEORY AND THEIR SPREAD THROUGHOUT ARGENTINE \\ POLITICAL THOUGHT
}

Ricardo Ramón Romero politologoromero@gmail.com Universidad de Buenos Aires - Universidad de Ciencias Sociales y Empresariales

Cómo citar este artículo / Citation: Romero, R. (2016). "Democracia, república y libertad. Aproximaciones desde la teoría politica moderna e irradiaciones del pensamiento político argentino". Revista Científica Arbitrada de la Fundación MenteClara, 1 (2), 8-25. DOI: 10.32351/rca.v1.2.14

Copyright: (C) 2016 RCAFMC. Este artículo de acceso abierto es distribuido bajo los términos de la licencia Creative Commons Attribution-Non Commercial (by-cn) Spain 3.0. Recibido: 16/3/2016. Aceptado: 20/04/2016 Publicación online: 20/07/2016

\section{Resumen}

Este trabajo se propone el análisis de los vínculos existentes entre libertad, democracia y república. Esta tríada está compuesta por conceptos fundamentales para la teoría política y el pensamiento liberal. Sin embargo, al no querer considerarla una trinidad, deberíamos analizarla críticamente como una trilogia, y que necesariamente se contrapone a otra compuesta por igualdad, poder y propiedad, que en cierta medida amplia la conceptualización.

\begin{abstract}
This work is intended to analyze the links among freedom, democracy and republic. This triad is made up of fundamental concepts for political theory and liberal thought. However, since we do not want to consider it as a trinity, we should analyze it critically as a trilogy, concept that is necessarily opposed to another trilogy made up of equality, power and property, which broadens the conceptualization.
\end{abstract}

\section{Palabras Claves/ Keywords}

Teoría Política; República; Democracia; Libertad; Ciencia Política; Political Theory; Republic; Democracy; Freedom; Politic Science 
DEMOCRACIA, REPÚBLICA Y LIBERTAD. APROXIMACIONES DESDE LA TEORÍA POLITTICA MODERNA E IRRADIACIONES DEL PENSAMIENTO POLITICO ARGENTINO

\section{Libertades o Igualdades}

Libertades o igualdades es dificil la elección, tal vez sea necesario que decida el corazón.

Yo sé que vos aun sentís que puede haber otro destino, este final, no es la final; hay que empezar otro partido. Igualdad + libertades debe ser la solución, siempre brotan nuevos sueños en el medio del dolor...

Donde estará la verdad, quién la podrá tener; una enseñanza nos quedará, nadie se banca que le digan lo que hacer.

Libertades o igualdades es vivir sin la elección, tal vez sea necesario que decida el corazón. Libertad + igualdades debe ser la solución siempre brotan nuevos sueños en el medio del dolor.

Falta y resto, Murga Uruguaya 


\section{A manera de presentación: de trilogias a hexalogias}

Nos proponemos entrar en el análisis de los vínculos existentes entre libertad, democracia y república. Esta tríada, está compuesta por conceptos fundamentales para la teoría política y el pensamiento liberal.

Sin embargo, al no querer considerarla una trinidad, cayendo en una mirada religiosa, deberiamos analizarla criticamente como una trilogia, que necesariamente se contrapone a otra, compuesta por igualdad, poder y propiedad, que en cierta medida amplía la conceptualización.

Si hablamos de libertad, necesariamente tenemos que pensar la trascendencia que implica la posibilidad de ejercerla, a partir de la condición de igualdad.

En tanto, que las decisiones que se toman en el gobierno, están limitadas por las relaciones de poder, que condicionan la democracia. Y si tenemos en cuenta que las leyes establecidas en la república en tiempos de la modernidad, tienen como base principal garantizar el resultado de la propiedad privada, no cabe duda que debemos extender la mirada.

A partir de éstos conceptos, podemos recorrer el pensamiento moderno, viendo las tensiones abiertas en las problemáticas que enfrentaban los teóricos que buscaban brindar la legitimidad y al nuevo tipo de gobierno emergente del Estado moderno, se trata de los mismos inconvenientes que tienen que enfrentar nuestros pensadores argentinos y que intentaremos incluirlos en los ejes propuestos.

Este ensayo se desarrolla en tres aproximaciones que parten del análisis de los conceptos, desde el intento fundacional del gobierno, especialmente bajo el marco del contractualismo, para luego estudiarlos en el proceso de la formación del gobierno representativo, como especie de sintesis entre democracia y república. Finalizamos nuestras reflexiones desde las visiones críticas a la democracia o al gobierno representativo.

Debemos alertar, que el análisis se concentra fundamentalmente en los conceptos seleccionados a través de algunas aseveraciones vertidas por los autores citados, teniendo presente el contexto histórico que los enmarcaron. Para evitar una exposición escolástica, intentaremos una imbricación expositiva, casi como un caleidoscopio, posibilitando una lectura diacrónica y sincrónica de los mismos. 
Primera aproximación: Constitución del gobierno en los albores de la teoría política moderna

Encontramos en el pensamiento de Maquiavelo un proceso de secularización de la política, que rompe con el principio de legitimidad religiosa y la aparición del individualismo que se produce en los albores de la modernidad; en el contexto de la guerra civil inglesa 1648; la revolución francesa y la independencia norteamericana 1776, y antesala de los comienzos de nuestra patria.

La preocupación subyacente en esas reflexiones, se concentra en encontrar un nuevo principio de legitimidad para un gobierno secular, que ya no lo da Dios, sino que debe ser instituido por los individuos.

Siguiendo este hilo, se parte de un momento previo a la constitución del cuerpo político y del gobierno, definido como estado de naturaleza en el cual todos los hombres viven en estado de plena libertad e igualdad y no tienen nada que obedecer, para pasar a la constitución de un soberano, que a la vez se busca no perder la condición esa libertad e igualdad que los constituye como individuos.

Ese momento, que los primeros contractualistas llamarian "estado de naturaleza", donde la falta de seguridad que compele a los individuos, los lleva a reflexionar sobre las condiciones de un pacto social que instituya el gobierno.

Aunque el motivo y la condición cambiaba según fuera la visión de cada pensador. Para Hobbes, los hombres se encuentran en plena igualdad (Hobbes, 2003, p. 124), pero esa situación provoca una inseguridad, por la tendencia que los mismos tienen a enfrentarse por la supervivencia (Hobbes, 2003, p. 124).

De esta manera, esta libertad plena que se puede ejercer, como derecho natural, provoca la guerra entre los hombres (Hobbes, 2003, p. 130). Por su parte Locke coincide con Hobbes sobre la existencia de la plena libertad e igualdad en el "estado de naturaleza" (Locke, 1996, p. 205), sin embargo, no parte de una situación de enfrentamiento entre los hombres, sino, de la ausencia de un juez con capacidad para dirimir en los conflictos entre los ellos por el ejercicio de la propiedad (Locke, 1996, p. 211-16).

En una misma línea argumental sigue Rousseau, quien sostiene que el hombre en estado de naturaleza no es malo (Rousseau, (A), 2001, p. 96), sino, que la propiedad genera los enfrentamientos entre los hombres (Rousseau, (A), 2001, p. 107), y citando a Locke, 
dice: "no puede haber agravio donde no hay propiedad" (Rousseau, (A), 2001, p. 114).

Montesquieu se suma a la crítica a Hobbes, donde entiende que por el contrario, en el "estado de naturaleza", los hombres tienen una necesidad de aproximación $y$ no de enfrentamiento (Montesquieu, 2004, p14).

Estas diferentes visiones sobre el estado de naturaleza, genera distintas razones para la constitución del gobierno. Para Hobbes, los hombres, a través de un acto voluntario, establecen un pacto de asociación y sujeción, por el que renuncian su derecho de libertad a un soberano (Leviatán), encargado de garantizar su seguridad (Hobbes, 2003, p. 131).

En tanto, que Locke sostiene que no se transfiere el derecho natural de libertad (Locke, 1996, p. 219). En este sentido, se establecen dos contratos, el primero de asociación y el segundo de sujeción. La novedad de este contrato es que el soberano también pacta, obligándose a obedecer las mismas leyes.

Si para Hobbes, la república se instituye para preservar la vida (Hobbes, 2003, p. 161), para Locke, el gobierno civil preserva la propiedad, entendida como derecho a la vida. La libertad y propiedad es obtenida en justo derecho a partir del trabajo del hombre (Locke, 1996, p. 228).

Por su parte, Rousseau plantea dos pactos, el pacto inocuo, implica el pasaje del estado de naturaleza a la sociedad civil, en el mismo, los propietarios engañan a los no propietarios para garantizar su propiedad, el segundo pacto, el contrato social supone el traspaso de la sociedad civil, estadio de injusticia y desigualdad a la república, como estado de armonía social.

De esta manera, el acuerdo de asociación es para garantizar la plena libertad y la igualdad de los hombres, evitando el abuso de uno sobre otro (Rousseau, (A), 2001, p. 114). Libertad que ahora deviene en leyes que la garantizan, afirmaria Montesquieu (Montesquieu, 2004, p. 130).

Un jacobino criollo, Mariano Moreno, quien entiende a la ciencia politica como: La sublime ciencia que trata del bien de las naciones, es el primer hombre que reflexiona, en plena emancipación argentina, sobre las bases de esta nueva nación. Asevera que la libertad se constituye en plena igualdad de los hombres, que un pueblo esclavo que rompe sus cadenas debe tomar conciencia sobre las leyes. Y que es el pacto social la única base de obediencia y el 
conocimiento de los derechos permitiría la superación real de la tiranía (Moreno, (A), 1998, p. 135).

Constituido el gobierno, éste establece una relación con los devenidos súbditos, para Hobbes, o pueblo, para Rousseau, o ciudadanos, para el resto. La teoría de Hobbes plantea una delegación absoluta del poder político, donde el soberano no pacta con los contratantes (Hobbes, 2003, p. 167), se sostiene que el derecho natural no se transfiere, siempre queda latente el derecho a la autodefensa (Hobbes, 2003, p. 137).

Sin embargo, está convencido que la república es un pacto por el bien común (common wealth) cree que la libertad es compatible con el poder ilimitado del soberano, porque es éste el que la garantiza (Hobbes, 2003, p. 199).

Por su parte, Locke sostiene que la república, constituida por la Sociedad Política, se produce sin delegación de libertad por el pleno consenso del pueblo (Locke, 1996, p. 219/ 275). Además, Locke sugiere moderar ese poder político a través de la separación de las funciones legislativas de la ejecutiva (Locke, 1996, p. 300).

En esa línea, también está de acuerdo Montesquieu, sigue la misma linea de pensamiento y entiende que la libertad se asienta sobre la división de poderes (Montesquieu, 2004, p. 132).

En Rousseau, el poder reside en el conjunto del pueblo, el gobierno intercede entre el Estado, la voluntad general y el pueblo. El gobierno es un producto de la voluntad general, que se constituye con la superación de las voluntades particulares o sea dejando las diferencias y alcanzando la igualdad (Rousseau, (B), 2001, p. 196).

El contrato social de Rousseau supone la cesión de todos los derechos naturales, aun el derecho a la vida. Esa cesión integral de cada uno a la comunidad, los iguala, de ese modo desaparecen los intereses particulares y todos conformando la voluntad general buscarán el bien común.

Su república está sustentada en las leyes dictadas por la voluntad general constituida por leyes (Rousseau, (B), 2001, p. 207), cuyo fin es asegurar la libertad e igualdad, que para Rousseau se constituye en la obediencia a la ley (Rousseau, (B), 2001, p. 219).

Aunque explicita, que el poder legislativo pertenece al pueblo reunido como voluntad general y sólo a él (Rousseau, (B), 2001, p. 223). En este sentido, el gobierno recibe de la soberana voluntad general las órdenes de gobierno (Rousseau, (B), 2001, p. 224). 
Nuevamente el joven jacobino, nos plantea que el gobierno debe generar una relación con el pueblo, debe desplegar una "comunicación pública" capaz de vincular los actos de gobierno con la voluntad del pueblo (Moreno, (B), 1998, p. 142). Considera que los ciudadanos no deben hacer una mera delegación de funciones, nos dice: "es cierto que el pueblo debe esperar todo lo bueno de sus representantes, pero deben aprender por si mismos lo que es debido a sus intereses y derechos" (Moreno, (C), 1998, p. 198).

Constituida república, se impone pensar en su forma, y aquí Hobbes retoma una variable clásica de tipificación aristotélica, relacionada con la cantidad de personas que integran el gobierno, si es uno, se trata de una monarquía, si es una parte de la sociedad será una aristocracia y si es todo el pueblo resultará una democracia, plantea que existen deformaciones de los mismos en tiranía, oligarquía y anarquía. Exponiendo seis razones por la cual se acerca mejor al poder absoluto (Hobbes, 2003, p. 174-6).

Por su parte, Locke sostiene que una vez reunidos los hombres en sociedad, la mayoría, los propietarios, tienen el poder de establecer quienes dictan las leyes y los ejecutores de las mismas. Si ésta mayoría emplea su poder en dictar y ejecutar, es una democracia perfecta, si en cambio, delega en manos de unos pocos hombres, es una oligarquía, y si lo hace en una persona, es una monarquia, hereditaria si es el poder reside también en su herederos o electiva si el cuerpo elige su sucesor (Locke, 1996, p. 298). Pero no se concentra en optar por una forma, sino por dar pautas claras del ejercicio del legislativo, que es el poder supremo de la república (Locke, 1996, p. 313).

Para la división de los gobiernos, Rousseau opta por el mismo criterio, el número de miembros que lo componen. Cuando todo o gran parte del pueblo participa de él, es una democracia, cuando se deposita en un pequeño número, una aristocracia, y si recae en una persona, una monarquía (Rousseau, (B), 2001, p. 231). Y si bien, por su concepto de voluntad general, uno pensaría que el ginebrino optaría por la democracia, éste la considera como una forma perfecta e inexistente, y tras descartar la monarquia, sostiene, que la aristocracia, electiva, es la mejor forma de gobierno (Rousseau, (B), 2001, p. 234-43).

Por su lado, Montesquieu sostiene que las leyes derivan de la naturaleza de los gobiernos, los cuáles pueden calificar como: el republicano, el monárquico y el despótico. Esta clasificación mantiene el criterio de la cantidad de miembros que componen el gobierno, pero también distingue en la forma en que se gobierna. 
En el modelo republicano, cuando participa el pueblo entero, lo define como democracia, pero cuando lo hace una parte, lo llama aristocracia. En tanto que si gobierna una sola persona, puede ser monarquía o despotismo, pero se diferencian por la vigencia de leyes en el primero (Montesquieu, 2004, p. 24-25).

Paradójicamente, Montesquieu no tomará a las formas republicanas como más adecuadas para preservar la libertad política, sino que entenderá que los gobiernos "moderados", por ende la monarquía, garantizan la efectividad de acción del ejecutivo, asi como el pleno ejercicio de la libertad. Sin embargo, el legislativo, aclara, debe estar en manos de varias personas (Montesquieu, 2004, p. 131-135/6). Este análisis nos lleva a pensar su preferencia por la monarquía constitucional inglesa, emanada de la gloriosa revolución 1689.

En la exposición sobre las formas de gobierno, encontramos cierta moderación en los pensadores europeos y una osadia en el argentino Esteban Echeverria. Mientras los autores del viejo continente no visibilizan a la democracia, como una alternativa de gobierno, el joven romántico se juega por ella. Sostiene, que los principios de libertad-igualdad-fraternidad son esenciales en la base simbólica de la construcción de la patria (Echeverría, 1948, p. 108).

Entiende, que la recuperación de los ideales de mayo de 1810 se expresa en la organización de la patria sobre una base democrática (Echeverría, 1948, p. 149). Y esta superación necesita de una confraternidad de intereses a través de una fusión de acuerdo de las partes enfrentadas en la historia (Echeverria, 1948, p. 168).

Podemos concluir con esta primera aproximación, diciendo que el punto esencial del gobierno reside en la constitución de la república. El marco brindado por las leyes, que garantizan derechos que prioritarios de este nuevo estado político, donde valores como la libertad e igualdad presentes en la estado natural, son desplazados por derechos creados, como la propiedad privada, o habilitados por medio de la ley. 


\section{Segunda aproximación: formación del gobierno representativo}

Se expusieron algunas consideraciones realizadas sobre la mejor forma de gobierno, y observamos que coinciden en la preocupación sobre la igualdad, esencialmente democrática, que impulsa a considerar a la totalidad del pueblo como un conjunto de ciudadanos de plenos derechos. Sin embargo, se avanza a mediar los intereses a través del sistema de representación, concepto recuperado por Locke para legitimar los intereses de los propietarios (burgueses) en la arena política. O sea, la figura del "pueblo" irá cristalizando en un mecanismo de contralor, a través de un gobierno que lo representaría, lo que nos invita avanzar en una segunda aproximación, que analice los alcances del concepto de "gobierno representativo".

La pesadilla que tenían los primeros teóricos modernos, sobre el involucramiento del pueblo en la politica, se hizo realidad con la radicalización democrática de la revolución francesa. Tras este acontecimiento, la democracia, como "gobierno del pueblo" en abstracto, comenzaría a repensarse como "gobierno representativo" en concreto. No por un desliz hegeliano objetivante, sino por una tendencia histórica inevitable hacia la democracia, como afirmaria Alexis de Tocquevelli años subsiguientes (De Tocquevelli, 2005, p. 35).

Pensar en una idea de elección del gobierno, era considerada por Burke como una palabrería aduladora. Lo vemos cuando critica el discurso del sacerdote Dr. Price (Burke, 1996, p. 53), Burke desacredita la propuesta de mismo, al sostener que en la Bill of Rights (Declaración de Derechos) de la revolución inglesa, no se avanzaba hacia un principio de elección (Burke, 1996, p.56). Aclara Burke, que si bien se entiende que el rey es servidor del pueblo, sin embargo, éste no debe obedecer ninguna otra persona y los súbditos deben su obediencia legal a él (Burke, 1996, p. 65).

Desde otro ángulo, paradójicamente siguiendo a Rousseau, y bajo la idea que la voluntad nacional no puede ser delegada, De Maistre entiende que en la representación, el pueblo queda esclavo y amordazado por un gobierno aristocrático, usurpador de la autoridad (De Maistre, p.44-45). Amplia de Maistre, al sostener que ninguna gran institución resulta de una deliberación. De esta manera, ningún legislador podría hacerse obedecer, ni por la fuerza, ni por el razonamiento; Así entiende que un poder no puede establecerse a través de una república (De Maistre, p. 73). A1 defender la monarquía, propone poner atención en el caso inglés, donde no se suprimió a la realeza para garantizar la libertad. Por 
ende, entiende que sería un buen paso para Francia restablecer la legitimidad del gobierno y recuperar la monarquía (De Maistre, p. 86 y ss).

Contrario a esta visión, y partiendo de una crítica a Rousseau, Constant entiende que sólo al seguir las máximas comprendidas en la libertad antigua, se puede sostener que los ciudadanos deben estar involucrados en el gobierno para garantizar que una nación sea totalmente soberana. Y sostiene que en los tiempos modernos, rescatando la visión de Montesquieu, los ciudadanos quieren disfrutar de su vida, por lo que delegan la administración de lo público (Constant, 1989). En este sentido, Constant construye la figura de "libertad política" para las instituciones constituidas libremente por los individuos, y que se centran en garantizar ese disfrute de lo privado (Constant, 1989).

De esta manera, de a poco nos alejamos de la idea del autogobierno, el mismo Sieyes que sostenía que el tercer estado quería ser todo, entiende no es posible, y que el gobierno sólo puede ser ejercido por delegación (Sieyes, 2003, p. 82 y ss). Siguiendo este planteo, la legitimidad de la república, ya no reside en el acuerdo entre individuos, sino, en la capacidad del gobierno representativo de relacionarse con el pueblo. Asimismo, el principio del sorteo, como selección de los magistrados en la democracia, es relevado por el de elección, generalmente reservado para gobiernos aristocráticos, basado en el apotegma que la voluntad del pueblo es la que define una forma de gobierno, y esa voluntad lo que la sostiene (Mills, 1878, p.12).

Encontramos así, una nueva aproximación a los conceptos de república y libertad, donde debemos tener presente, que el pueblo, no será cualquier persona, sino aquél capaz de hacer una buena elección del soberano. De esta manera, lo democrático de la administración, no devendrá de su participación directa del gobierno, sino, en la representación de sus intereses, lo que sería la mejor forma de gobierno (Mills, 1878, p. 67).

Es más, la república, no necesariamente debe asumir una forma democrática, en esa línea convergen Mills y Alberdi, sino que hay que privilegiar la constitución de un gobierno en base a la capacidad de un pueblo de sostenerlo, y que el fondo de su acción, sea la preservación de los derechos civiles (Alberdi, (C), 1970, p. 122). A su vez, agrega Sarmiento, que si bien las ideas revolucionarias se difundían por Sudamérica, la preocupación por la forma de gobierno no fue el principal objetivo de los lideres de la emancipación (Sarmiento, (B), 2001, 185). 
En lo que refiere a la soberanía del pueblo, de Tocqueville destaca, que en América la misma se ejerce a través de un sistema comunal descentralizado (De Tocqueville, 2005, P I, Cap. IV). Y que la base de garantía contra cualquier tiranía, se constituye en la libertad de asociación y de prensa (de Tocqueville, 2005, p. 199- ss y 206-ss). Puntos que comparte Mills, cuando suma la libertad de expresión (Mills, (A), 1980, p. 33 y 42). Por su parte, Alberdi sostiene que la libertad no reside sólo en voluntad, sino que requiere también inteligencia, es ésta la que emancipa a los pueblos (Alberdi, (A), 1998, p. 24). Entiende que Rosas es representante del pueblo, porque el mismo no ilustró su libertad (Alberdi, (A), 1998, p. 37-38). Así, la cultura pasa a ser un punto clave para la formación de un bueno gobierno, porque el pueblo en democracia tendería a apartar a los hombres distinguidos del poder, por lo cual es necesaria la educación y las costumbres para corregir estos errores (De Tocqueville, 2005, P II, Cap. V).

Esta postura lleva a Mills a proponer un sistema de voto plural, ponderado según nivel de educación (Mills, (B), 1878, p. 272). En línea con esta visión, la cultura de la civilización europea permitiría el funcionamiento de la República (Sarmiento, (A), 2005, p. 47). Coincidiendo, Alberdi propone impulsar la inmigración europea, como forma de garantizar el progreso de la república (Alberdi, (B), 2005, p. 59). Pero advierte Mills, que debe evitarse que gobierne sólo una clase (Mills, (B), 1878, p. 242), entiende que éste sistema no debe favorecer a una clase y anular al resto de la comunidad (Mills, (B), 1878, p. 275).

Mientras, Burke supone que para una representación adecuada deben también considerarse las diferencias de propiedad (Burke, 1996, p. 85), de Tocqueville sostiene que lo que facilita un estado social democrático en Estados Unidos, es fuerte principio de igualdad generado por la distribución de la herencia. (De Tocqueville, 2005, P I, Cap. III).

Y siguiendo con los representantes, Burke sostiene que luego de la elección de los miembros del gobierno, los mismos son fideicomisarios del pueblo, y que actúan en representación de "la nación" (Burke, 1996, p. 204). En un punto similar, Hamilton, al defender la república frente a la democracia pura, plantea que la elección de un pequeño grupo de ciudadanos puede discernir mejor el verdadero interés de su país (Hamilton, 2006, X). Visión que lleva a Alberdi a ver a los convencionales constituyentes no como representantes del pueblo, como finalmente queda nuestro preámbulo constitucional, sino de las provincias (Alberdi, (B), 2005, p. 201 y 223). Sin embargo, para Mills, que si bien prefiere un 
representante ilustrado, sustenta que debe existir cierto compromiso con los electores, a fin de mantener una moralidad politica (Mills, (B), 1878, p. 354).

De a poco, queda claro, que la elección popular de los representantes no constituirá necesariamente un "gobierno del pueblo". Y bajo la excusa de evitar una "Tiranía de una mayoria", la clase obrera según Mills (Mills, 1878, p. 375), se construye un elegante concepto: "check and balance" (pesos y contrapesos), So that?!. Sencillamente, una cuidadosa construcción de mecanismos de representación de intereses (Madison, X, 2006, p. 38). En este sentido, Mills recomienda un sistema de dos cámaras, disimiles en composición, que impliquen diferentes marcos de construcción de mayorias, a fin de dificultar mayorias automáticas (Mills, 1878, p. 368).

Por su parte, Mills recomienda la separación de la elección del cuerpo legislativo respecto del ejecutivo, para buscar otro contrapeso (Mills, 1878, p. 395). Al igual que Mills y recuperando a Montesquieu, Madison retoma la idea de división de poderes como base para la libertad, pero pensándola desde un mecanismo articulado, de mutuos controles (Madison, XLVII, 2006, p. 207). En el mismo sentido, Alberdi sostiene que a la elección y publicidad de actos de gobierno y la división de poderes es la base del gobierno representativo (Alberdi, (A), 1998, p. 114). Además, en el esquema de gobierno mixto, el Senado cumple una función de articulación de intereses provinciales con los nacionales, mediando en la construcción de la voluntad popular (Alberdi, (B), p.108; Hamilton o Madison, LXII, 2006, p. 261). Conjuntamente al coincidir en la idea de elección indirecta del ejecutivo, se concuerda en plantear una superioridad del legislativo mediante la constitución para garantizar la libertad (Hamilton, LXXIII, 2006, p. 311; Alberdi, (B), p. 128129).

Con éstos aportes, podemos concluir esta segunda aproximación, diciendo que el gobierno representativo parece, en cierta medida, encontrar un equilibrio entre república y democracia. Sin embargo, deja al pueblo como un elector de su gobierno, pero a la vez súbdito del mismo, que debiera ser su voluntad. Por el contrario, el gobierno mixto media sobre los intereses y decisiones tomadas por el pueblo, a través del derecho del sufragio. Lo que nos invita a pensar cuánto tiene de democracia la propuesta y cuánto de aristocracia. Aún más, en qué medida, los representantes gobiernas para el pueblo o lo hacen por sus intereses, lo que llevaria a otra "cracia", donde el pueblo no delibera ni gobierna, pero tiene libertad..., tiene libertad?!. 
Tercera aproximación: Crítica al Gobierno representativo y a la democracia

Los gobiernos representativos o parlamentarios, establecidos a finales del siglo XIX, irian sucumbiendo en la centuria siguiente a partir de la década del 20, desplazados por regimenes autoritarios diferentes a las monarquias, como el fascismo, el nazismo y el mismo estalinismo. Es claro, que éstas formas politicas de gobierno, rompen indudablemente con la república, la democracia y la libertad. Sin embargo, debemos poner en claro, que son expresiones críticas a la paulatina exclusión del pueblo en los asuntos públicos provocadas por las llamadas democracias liberales.

Crítica que podemos observar incluso desde una visión republicana, como la de Hannah Arendt. A partir de sus razonamiento, de ver que las revoluciones francesa e inglesa se hicieron en nombre de la libertad (Arendt, 2004, p. 36) Arendt plantea que no la alcanzan. Tras distinguir la idea de liberación, entendida como ruptura de una dominación, respecto de libertad, comprendida como libertad de acción garantizada por un gobierno (Arendt, 2004, p. 37), sostiene que la Revolución Francesa no alcanza la libertad, por el devenir de la tiranía (Arendt, 2004, p. 98). Y si bien, la revolución norteamericana logra establecer marcos institucionales para la libertad (Arendt, 2004, p. 190), paulatinamente se pierde ese tesoro en el gobierno mixto, donde el pueblo se retira de la esfera pública (Arendt, 2004, p. 328).

Otro punto crítico, lo aporta Silvio Frondizi, quien ve que el principio de autogobierno, surgido en los albores de la modernidad, y expresado por Mariano Moreno en su defensa de la autodeterminación de los pueblos, quedó clausurado con la sanción de la Constitución de 1853, especialmente en el art. 22, que versa: "E1 pueblo no delibera ni gobierna si no por medio de sus representantes...". Entiende Frondizi, que es imprescindible la derogación del art. 22, para el ejercicio de la soberanía popular a través de una democracia directa. Y sugiere la redacción de un principio que: "debe ser el pueblo por si mismo, y cuando lo cree conveniente, delega algunas funciones en representantes" (Frondizi, (A), 1958, p. 113).

Desde otro ángulo, Carl Schmitt arremete contra los gobiernos liberales, por la tendencia a la "despolitización" que los mismos generarian. Según Schmitt, en la propuesta liberal, se pierde la relación intrínseca entre estado y política. El liberalismo impide la distinción y especificidad de lo político, y su existencia misma, al volver difusa la frontera entre estado y sociedad (Schmitt, (A), 1998, 
p. 53). El intento de disolver la oposición amigo-enemigo, esencial y constitutivo de lo político, reduce a los individuos a un aspecto económico, como competidor, o a una instancia espiritual, como un oponente en la deliberación. Y si bien es verdad que en lo económico puede ser que todos se vean como competidores, lo cierto es que los pueblos se perciben como amigos o enemigos, lo que da punta pie a la política (Schmitt, (A), 1998, p. 58). Por eso rechaza la propuesta pluralista entendiendo que una tendencia así provoca la negación de la unidad soberana del estado (Schmitt, (A), 1998, p. 70).

Hasta aquí, las críticas al gobierno representativo pareciesen ser abstractas y no prácticas. Sin embargo, cuando se analiza el funcionamiento parlamentario y la conformación de los partidos, podemos ver otras deficiencias en el desarrollo de la república democrática. Especialmente, entiende Weber, con la burocratización y formación de los partidos políticos. (Weber, 2003, p. 275). Con la burocratización de los partidos, el parlamento se convierte en un espacio de patronazgo y clientelismo (Weber, 2003, p. 281). El presupuesto democrático que tendria el parlamento (Weber, 2003, p. 294) se desplaza, según Weber, hacia la lucha política por la obtención de cargos (Weber, 2003, p. 304).

En la misma linea, postula Arendth que el Partido convierte el gobierno representativo en un gobierno de "pocos" (Arendth, 2004, p. 372). Aclarando previamente que Arendth entiende que las necesidades limitan el desarrollo de la polis (Arendth, 2004, cap. 2), sostiene que en una sociedad de abundancia, los intereses de grupos no necesitan resolverse a costa de otros, por ende, el sistema de partidos sólo genera incompetencia y despilfarro (Arendth, 2004, p. 377), y agrega, que el sistema de partidos reemplaza la idea de "gobierno del pueblo y por el pueblo" por otra: "gobierno del pueblo por una elite que procede del pueblo" (Arendth, 2004, p. 372).

Por su parte, Schmitt ve a que la factibilidad de una definición de politica como politica de partido es posible: "cuando empieza a perder fuerza la idea de una unidad politica (del Estado) capaz de relativizar a todos los partidos" (Schmitt, (A), 1998, p. 62). Sumando a su visión, Schmitt plantea una crítica al mecanismo de sufragio secreto por el cual se elige a los partidos, entiende que aquí se pierde la representación del pueblo por una sumatoria de voluntades privadas (Schmitt, (B), 1992, p. 240). A su vez, sostiene que la democracia tiene algunos límites: la imposibilidad de la relación identidad - representación; la naturaleza de un pueblo; los temas sobre los que se decide; y, fundamentalmente, la idea que la 
mayoría decide implica un planteo sobre quienes deciden (Schmitt, (B), 1992, p. 268 y ss).

Contrario a esto, Gramsci entiende que un partido puede ser una base organizativa de una voluntad colectiva (Gramsci, (A), 1993, p. 70). De esta manera, retomando a Maquiavelo quien proponía un jefe (Partido en este caso) para educar al "que no sabe", identificado por Gramsci como: "la clase revolucionaria de la época, el "pueblo", la "nación", en definitiva (digo), la democracia urbana..." (Gramsci, (A), 1993, p. 72). Por lo que el partido tiene importancia si logra estar en momentos decisivos de la historia de un país (Gramsci, (A), 1993, p. 83). Pero esto, supone salir de un centralismo orgánico (intento de dominio de una parte al todo) por un centralismo democrático, que implica una inserción de la organización al movimiento real, (Gramsci, (A), 1993, p. 145). Así, en esa definición, Gramsci expone a la disciplina como una asimilación consiente y lúcida de las directrices a realizar, disciplina que no anula la libertad y personalidad, porque su origen es democrático (Gramsci, (B), 1993, p. 188-89).

Una construcción democrática desde la sociedad civil, o el pueblo, sería retomada por Silvio Frondizi, quien impulsó la praxis de la autogestión, a través de su militancia en organizaciones locales, sociedades de fomento, juntas comunales y municipios. Siguiendo ésta práctica, comprendió teóricamente que para una democracia autogestionaria "...es de fundamental importancia promover nuevos órganos, comités o concejos, de contenido realmente popular, con funciones de acción y de poder...". Para Frondizi, estas instancias debian "...promover la participación activa y reagrupamiento de las bases obreras y populares, para su intervención directa en la vida social y política, y su preparación para el ejercicio del gobierno..." (Frondizi, (B) p. 161).

Como vemos en esta aproximación, la soberanía popular es reclamada para el pueblo. Por ende, se comprende que la construcción democrática se constituye esencialmente a partir de la participación popular en el gobierno. Quizás otras visiones como la de Dahl, que prefiere hablar de poliarquía antes que democracia, o Hayek que sigue con la idea que todo estado limita la libertad, e incluso Laclau, para sumar un argentino, que realiza una crítica al marxismo tradicional, hubiesen profundizado éste abordaje, más aún en las transformaciones de las democracias liberales en el marco del Estado de Bienestar (Laclau, 2004). Aunque esa tarea queda pendiente. 


\section{A manera de conclusión: De trilogía a trilogía}

La exposición de cada aproximación tuvo un correlato histórico, la construcción del gobierno durante el siglo XVIII; el gobierno representativo durante el siglo XIX; y la crítica democrática durante el siglo XX. Podemos ver ésta situación como una mera coincidencia o como un proceso evolutivo. Cuando en la introducción nos deteníamos a pensar sobre la trilogía propuesta libertad- república y democracia, se sostuvo que era necesario ampliarla hacia una hexalogía que sume los conceptos de igualdad- propiedad y poder. Ejes que fueron tomados en cuenta a lo largo del análisis de los autores. Sin embargo, luego de la exposición analítica, podemos ver un desplazamiento en la preocupación teórica de los autores, que nos darian la razón sobre la idea de un proceso evolutivo del pensamiento politico.

Si durante el siglo XVIII, las reflexiones hacian pivote en la trilogía libertad - república y propiedad, sin duda, podemos ir viendo, que durante el siglo XX, la deliberación política desplaza su epicentro a otra trilogía basada en la igualdad - democracia y poder. Entrando al siglo XXI, con el resurgir del neoliberalismo, observamos una nueva preocupación sobre la libertad y la república, ahora sí, sumada la democracia, porque no se puede desechar y es un desafio conceptual que tienen los teóricos contemporáneos. Sin embargo, aquí reitero la necesidad de no abandonar los otros puntos conceptuales. Creo que un abordaje teórico no puede prescindir de buscar convergencias entre éstos seis ejes.

El análisis se podría profundizar con conceptos como estado de bienestar o socialismo, sin embargo, se centró en esa trilogía para ver la forma evolutiva, o sea social e histórica, de los conceptos, y afirmar que en la figura de ciudadano se concentra: sus derechos políticos, en el marco de la república y la democracia, y sus derechos civiles, bajo la idea de libertad e igualdad. Pero el gran problema reside en el poder que puede generar la propiedad. Creo sustancial analizar el poder individual que provoca la propiedad y los efectos que tienen en la diferenciación de la sociedad. Y sostengo que es fundamental el estudio del estado como mediador de éste conflicto, lo que llamaria a profundizar una nueva trilogia: individuo-sociedad y estado, que será parte de otro artículo. 


\section{Referencias}

Alberdi, J. (A), Fragmento preliminar al estudio del Derecho (1837), Editorial Ciudad y Cultura, Bs. As., 1998; (B) Bases y puntos de partida para la organización politica argentina (1852), Edic. Libertador, Bs. As. 2005; (C) La monarquía como mejor forma del gobierno en Sudamérica (1861-3), Ed. Peña Lilho, Bs. As. 1970.

Arendt, H. Sobre la revolución (1965), Alianza, Bs. As. 2004.

Burke, E. "Reflexiones sobre la revolución de Francia y sobre la actualidad de ciertas sociedad de Londres respecto a ese acontecimiento. En carta destinada a un caballero de París" (1790), Escritos Políticos, FCE, México, 1996.

Constant, B. "De la libertad de los antiguos comparadas con los modernos" (1819), Centro de Estudios Constitucionales, 1989.

De Maistre, J. Consideraciones sobre Francia (1796), Tecnos, Madrid, 1990.

De Tocqueville, A. La democracia en América (1835), FCE, México, 2005.

Dahl, R. (1971), Poliarchy: participation and opposition Yale U. Press: New Haven

Echeverría E. Dogmas Socialista (1837), Editorial Estada, 1948.

Frondizi, S. (A) "La reforma constitucional", Doce años de politica argentina, Praxis, Bs. As. 1958; (B) "Bases y puntos de partida para una soberanía popular", Edit. Ciencias Politicas, Bs. As., 1961.

Gramsci, A. (A) "El Príncipe Moderno" y (B) "Notas sobre la política y el Estado Moderno" (1949), La politica y el estado moderno, Planeta, Bs. As., 1993.

Hamilton, Madison y Jay, El Federalista. (1780), FCE, México, 2006.

Hayek, F. (1944), Camino a la servidumbre, Routledge Press, Reino Unido.

Hobbes, T. (1651), Leviatán, Losada-Página/12, I y II, Bs. As., 2003.

Laclau, E y Mouffe, C. (2004) Hegemonía y estrategia socialista: hacia una radicalización de la democracia. Fondo de Cultura Económica.

Locke, J. (1690) Dos ensayos sobre el gobierno civil, Planeta DeAgostini, España, 1996.

Mills, J. (A) Sobre la Libertad (1859) Aguilar, Bs. As., 1980; (B) El gobierno representativo, Madrid, 1878.

Montesquieu, C. Del Espiritu de las Leyes (1748) Ediciones Libertador, Bs. As., 2004.

Moreno, M. (A) "Prólogo al Contrato Social" (1810), (B) "Fundación de la Gaceta de Buenos Aires" (1810), (C) "Sobre las miras del Congreso que acaba de convocarse y Constitución del Estado" (1810), en Representación de los hacendados y otros escritos, Emecé, Bs. As., 1998.

Rousseau, J. (A) Discursos el origen de la Desigualdad de los hombres (1755), (B) El contrato social (1762), Editorial El Ateneo, 2001.

Sarmiento, D. (A) Facundo. Civilización y Barbarie (1845), Bureau Ed. Bs. As., 2005; (B) Conflicto y armonías de las razas en América (1883), Obras Completas, UNLM, Bs. As., 2001.

Schmitt, C. (A) El concepto de lo político (1932), Alianza, 1998; (B) Teoría de la Constitución, Caps. 17-21. Madrid: Alianza 1992. 
Sieyes, E. (2003) ¿Qué es el Tercer Estado? (1788-9), Fontana, Bs. As.

Weber, M. (2003), "Parlamento y gobierno en una Alemania reorganizada" (1918), Obras selectas, Distal.

Articulo patrocinado por las Escuelas de Tantra de Argentina y España 